\title{
Social, economic and environmental inequalities in coastal communities: understanding the context for integrated management
}

\author{
Alex Midlen, CoastNet
}

In modern western democratic society the processes of governance are largely directed towards the reduction of inequalities in wealth. These inequalities are often causal factors in further inequalities of health, education, skills, individual contribution to society, and democratic engagement. Environmental inequalities can exacerbate inequalities of wealth in contrasting ways: communities may be rich or poor in environmental resources that may be exploited to create wealth, or the intrinsic value of environmental resources may be such that they are protected and not available for wealth creation. In this latter case, their very occupation of physical space that may otherwise have been occupied by exploitable resources is a further inequality.

In order to manage the coast in an integrated way it is the responsibility of government and its institutions to understand these inequalities so that management interventions are effectively directed towards their eradication in a sustainable manner.

To date European research (and policy) have concentrated largely on understanding the nature of the natural environment of the coast. Little effort has been directed at understanding the social condition of coastal communities, the internal dynamic of coastal economies or their wider role in national economies.

This paper draws on experiences in the UK to illustrate the nature of some of these social, economic and environmental inequalities, and to suggest ways in which they might be better addressed through processes of integrated coastal management. 